\title{
Evaluation of Light-curing Intensity Output and Students' Knowledge among Dental Schools in Riyadh City
}

\author{
Sultan Binalrimal ${ }^{1 *}$, Sarah Alamry $^{2}$, Mona Alenezi $^{2}$, Nora Alfassam $^{2}$, Sara Almuammar $^{2}$ \\ ${ }^{1}$ Assistant Professor, Department of Restorative Dentistry, Riyadh Elm University, Riyadh, Saudi Arabia; ${ }^{2}$ Dental intern, Riyadh \\ Elm University, Riyadh, Saudi Arabia
}

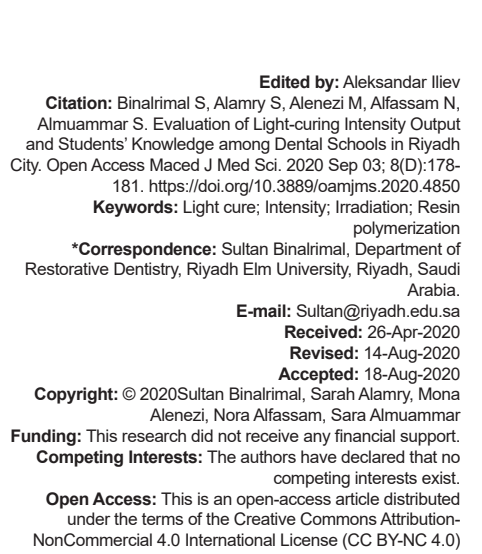

Introduction

The dependence on light-curing units increased with the higher demand for bonded restorations, for they are now the most used restorative material for posterior and anterior restorations [1]. Visible light-curing (VLC) units (light-curing unit [LCU]) became an essential part of everyday dental practice. Many factors affect the adequate polymerization of a resin composite restoration; LCU-related, composite-related, and practitioner-related. The factors relating to the LCU, the irradiance, and type of LCU influence the photopolymerization of the composite restoration. The type of resin, the filler particles, and the shade are the restoration-related factors. As for the factors regarding the dentist's use of LCU, the duration of exposure, the amount of distance from the LCU to the tooth, and the positioning of the LCU tip (perpendicular to the surface of the restoration), all play an important role in the success of the resin composite restoration [2], [3], [4]. The inadequacy of light intensity also affects the microhardness and the color stability of the resin composite [5].

There are many forms of continuous curing techniques some of which are: Uniform continuous cure (light of moderate-intensity is applied for a period of time, it is the most commonly used form), step cure (first we start with low energy then step up to higher energy), and ramp cure (low-intensity light is applied at first then the intensity increases gradually-it decreases polymerization shrinkage). The other type of curing techniques would be discontinuous cure technique or pulse delay cure. In this technique, the restoration receives a single pulse of low intensity light for a short duration. Then after waiting a couple of seconds it receives another pulse of longer duration and higher intensity. [6]. Maintenance is required because with lack of monitoring VLC units' qualities diminish over time resulting from heat buildup within the unit, bulb frosting, tip contamination with remains of composite, and sterilization problems [7], [8]. When the LCU's intensity is lower than $400 \mathrm{~mW} / \mathrm{cm}^{2}$, it means that the bulb is deteriorating and needs to be replaced [9].

A study conducted in governmental health institutions in Riyadh found that current light-emitting diodes (LEDs) showed higher intensities than earlier ones. And that is a result of the improved qualities of current LEDs in regard to higher light intensities and broader light spectrum [10]. Resin composites have photoinitiators that are activated by the LCU, the most common photoinitiator is camphorquinone. This component is activated by the light-curing device at a wavelength between 420 and $580 \mathrm{~nm}$ [11]. This range is only successful for composite increments less or equal to $2 \mathrm{~mm}$ in thickness. The depth of curing may vary for different composite materials which would 
be due to scattering of light at the particle interfaces and light absorbance by pigments in the resin-based material and photoinitiators [12]. New resin composites include additional photoinitiators that could be filled as a bulk (no need for increments), but they require higher wavelengths of at least $1000 \mathrm{~mW} / \mathrm{cm}^{2}$ [11]. Bulk-fill composite restorations could be placed in increments of $4 \mathrm{~mm}$ or more as they also have more sensitive photoinitiators [4].

A study conducted at the University of Eskisehir concluded that dentists have unsatisfactory knowledge of the properties of light-curing units which indicate a void in the dental education system [11]. With a radiometer, dental clinicians or dental assistants are expected to check the intensity of the light-curing device which should range between 400 and $520 \mathrm{~nm}$ [13]. VLC devices and their effects and maintenance are a topic not many researchers touched on in Riyadh city and that gap needs to be filled considering how essential that it is to consider the intensity of daily-used curing devices and how it could have negative effects on the pulp, the longevity of the restoration, and the likelihood of recurrent caries. Dental practitioners should have all the basic knowledge with regard to our topic. Therefore, it is more important to make sure dental students gather all the basics while they are still learning. With the improvements in LED devices and their higher intensities, students should be aware of the clinical effects of the high intensity of light-curing devices on the pulp before they start their clinical practice. There are no previous studies focusing on dental students' knowledge and information about light-curing devices and their effects on the tooth and restoration in Riyadh, Saudi Arabia.

Our aim in this study is to interpret the dental student's knowledge of LCU's from different universities and colleges in Riyadh city and evaluate the intensity that emits from the light source of many LED-curing devices in the clinics of dental schools in Riyadh, Saudi Arabia.

\section{Methodology}

Study was approved by the Institutional Review Board of Riyadh Elm University. IRB approval number RC/IRB/2019/294. One hundred eighty-two LED-curing devices from different dental school clinics in Riyadh city were randomly selected to have their light intensity output evaluated using (Demetron ${ }^{\circledR}$ L.E.D. Radiometer - Kerr) among dental school clinics in Riyadh city. The (Demetron $^{\circledR}$ L.E.D. Radiometer - Kerr) is a chairside radiometer calibrated from 0 to $2000 \mathrm{~mW} / \mathrm{cm}^{2}$, which will provide us a score for the range of intensity of the light-curing device.

The university hospitals that were visited are King Saud University Medical City, King Saud bin
Abdulaziz University Hospital, Dar Al Uloom University Hospital, Alfarabi colleges' dental clinics, and Princess Nourah Bint Abdulrahman University Hospital and Riyadh Elm University Hospital included three campus sites (An Namuthajiyah Campus, Olaya Campus, and Munisiya Campus). The inclusion criteria were only to include LED devices with them being the most commonly used devices in general and especially by undergraduate dental students. We excluded every other light-curing device such as plasma arc, quartz tungsten halogen, and laser VLC units. To standardize the methodology, a pilot study was performed before starting. Every device was preheated for $60 \mathrm{~s}$ before placing it above the radiometer. Then, it was perpendicular to the target on the radiometer, as close as possible without touching the surface. The LCU was turned on for $20 \mathrm{~s} 3$ times with $1 \mathrm{~s}$ to rest in between the readings to avoid overheating. An average from those three readings was calculated. After the final readings have been calculated, they then were categorized into three groups: The inadequate intensity with values equals of $<400 \mathrm{~mW} / \mathrm{cm}^{2}$, the marginal intensity with values between 400 and $850 \mathrm{~mW} / \mathrm{cm}^{2}$, and the adequate intensity with values equals or more than $850 \mathrm{~mW} / \mathrm{cm}^{2}$.

As for the second part of the study, a total of 325 questionnaires from dental students and interns all around Riyadh city were collected to evaluate their knowledge regarding light intensity output and using the Statistical Package for the Social Sciences (SPSS) that the findings were analyzed. The investigation began after an agreement between the research group and clinical directors of the targeted dental schools.

\section{Results}

We measured the intensity of 182 light cure devices from eight different dental schools around Riyadh city using the Demetron ${ }^{\circledR}$ L.E.D. Radiometer Kerr. The Statistical Package for the Social Sciences, version 26 (SPSS), was used to analyzes the findings to produce cross-tabulation statistics and descriptive statistics using a one-sample test. The statistical significance was up to $p=0.05, p=0$.

Out of the 182 LCUs, 22 units (12\%) measured inadequate intensity $\left(\leq 400 \mathrm{~mW} / \mathrm{cm}^{2}\right), 91$ units $(50 \%)$ measured marginal intensity (between 400 and $\left.850 \mathrm{~mW} / \mathrm{cm}^{2}\right)$, and $69(37 \%)$ measured adequate intensity (more than $850 \mathrm{~mW} / \mathrm{cm}^{2}$ ).

In addition, most of the respondents to the questionnaire were female. They constituted $73.9 \%$ of a total of 325 dental students and interns. Males were only $26.1 \%$. Furthermore, $88.4 \%$ were of Saudi nationality and $11.6 \%$ were non-Saudi. As for the academic level or year, $43.8 \%$ from all universities and colleges were interns and the rest were from the $4^{\text {th }}$ year 
$(14.2 \%), 5^{\text {th }}$ year $(23.2 \%)$, and $6^{\text {th }}$ year $(18.8 \%)$. Most of the students and interns did not think that LCU intensity had an effect on the tooth pulp (55.8\%) and they also reported not to know the minimum wavelength of light cure intensity (62\%). Table 1 summarizes the answers to the questionnaire gathered from all our target dental schools.

\section{Table 1: Students knowledge of using light cure}

\begin{tabular}{|c|c|}
\hline Questions and answers & Count, n (\%) \\
\hline \multicolumn{2}{|l|}{ Do you think that light cure intensity should be measured regularly? } \\
\hline Yes. & $274(84.57 \%)$ \\
\hline No. & $50(15.43)$ \\
\hline \multicolumn{2}{|l|}{ If yes, how often do you think it should be measured? } \\
\hline $1-3$ months. & $52(16.05 \%)$ \\
\hline 3-6 months. & $126(38.89 \%)$ \\
\hline 6-12 months. & $90(27.78 \%)$ \\
\hline More than 12 months. & $6(1.85 \%)$ \\
\hline \multicolumn{2}{|l|}{$\begin{array}{l}\text { What is the optimum distance for the tip of light-curing unit and filling } \\
\text { material? }\end{array}$} \\
\hline Touching the surface. & $37(11.42 \%)$ \\
\hline As close as possible to the surface without touching. & $227(70.06 \%)$ \\
\hline $3-5 \mathrm{~mm}$ above the surface. & $58(17.90 \%)$ \\
\hline More than $5 \mathrm{~mm}$ above the surface. & $2(0.62 \%)$ \\
\hline \multicolumn{2}{|l|}{ What is the minimum wavelength of light cure? } \\
\hline $300 \mathrm{~nm}$. & $75(23.15 \%)$ \\
\hline $400 \mathrm{~nm}$. & $122(37.65 \%)$ \\
\hline $450 \mathrm{~nm}$. & $127(39.20 \%)$ \\
\hline \multicolumn{2}{|l|}{ do you ever check the light cure tip before curing your restoration? } \\
\hline Yes. & $222(68.52 \%)$ \\
\hline No. & $102(31.48 \%)$ \\
\hline \multicolumn{2}{|l|}{$\begin{array}{l}\text { Do you think light cure intensity plays a role in the failure of risen } \\
\text { bonded restoration? }\end{array}$} \\
\hline Yes. & $291(89.81 \%)$ \\
\hline No. & $33(10.19 \%)$ \\
\hline \multicolumn{2}{|l|}{$\begin{array}{l}\text { How many seconds is needed for curing time for each increment of } \\
\text { composite restoration? }\end{array}$} \\
\hline $10 \mathrm{~s}$. & $17(5.25 \%)$ \\
\hline $20 \mathrm{~s}$. & $171(52.78 \%)$ \\
\hline 30s. & $59(18.21 \%)$ \\
\hline 40s. & $77(23.77 \%)$ \\
\hline \multicolumn{2}{|l|}{ Do you think increasing time or light intensity affects the pulp? } \\
\hline Yes, it could cause thermal irritation or damage. & $143(44.14 \%)$ \\
\hline No, pulp can't be affected by it. & $181(55.86 \%)$ \\
\hline \multicolumn{2}{|l|}{$\begin{array}{l}\text { When using darker shades of composite restorations (A3.5) or darker } \\
\text { you will need to: }\end{array}$} \\
\hline Use the same curing time. & $181(55.86 \%)$ \\
\hline Increase curing time. & $111(34.26 \%)$ \\
\hline Decrease curing time. & $32(9.88 \%)$ \\
\hline \multicolumn{2}{|l|}{$\begin{array}{l}\text { What can be the result of inadequate polymerization (you can choose } \\
\text { more than one)? }\end{array}$} \\
\hline Toxic reactions. & $29(8.4 \%)$ \\
\hline Allergic reactions. & $25(7.2 \%)$ \\
\hline Secondary caries. & $191(55.4 \%)$ \\
\hline Marginal leakage. & $252(73 \%)$ \\
\hline Marginal discoloration. & $163(47.2 \%)$ \\
\hline Tooth sensitivity. & $159(46.1 \%)$ \\
\hline Physical and mechanical proprieties of the material weakness. & $231(67 \%)$ \\
\hline Others. & $29(8.4 \%)$ \\
\hline
\end{tabular}

\section{Discussion}

The aim of our study was to interpret the dental student's knowledge of light-curing units from different universities and colleges in Riyadh city and to evaluate the intensity of the light output of LED-curing devices in dental school clinics in Riyadh, Saudi Arabia.

Most of the studies done about the intensity of light-curing devices and the time required for curing in private dental offices found that curing devices showed weak performances due to lack of maintenance, while the curing time was still constricted to only $20 \mathrm{~s}$ [1]. About $52.78 \%$ of the students in our study also constrict the curing time to $20 \mathrm{~s}$, but with no correlation to the intensity, although $18.21 \%$ cure their restorations for $30 \mathrm{~s}$ and $23.77 \%$ cure their restorations for $40 \mathrm{~s}$ also in no correlation to the intensity of the LCU. In 2019, in Punjab, India two-thirds of dentists did not use barriers for infection control on the light-curing tip, while only one-third of dentists did use barriers [9]. In comparison, $68.52 \%$ of our students answered yes on the question "Do you check the light cure tip before curing your restoration?." Moreover, although the percentage is more assuring than that concluded from the study done in Punjab, most if not all dentists and dental students should follow the infection control protocol and check the tips of the LCU every time that they attempt to use it.

A study in Riyadh city that was targeting private clinics to evaluate light cure intensities found that 18 units showed $\left(400 \mathrm{~mW} / \mathrm{cm}^{2}\right), 81$ units showed $(400-850$ $\left.\mathrm{mW} / \mathrm{cm}^{2}\right)$, and 101 delivered more than $\left(850 \mathrm{~mW} / \mathrm{cm}^{2}\right)$. Most of the dentists showed a lack of awareness and claimed that they do not measure their devices' light intensity outputs. Most of them also had no knowledge of the minimum accepted wavelength in an LED device [14]. The devices with adequate intensity were the larger percentage, while, in our study, the large percentage was the devices of marginal intensity (91 units [50\%]). The previously mentioned findings agree with the findings that we concluded from the questionnaires in our study, the only difference being that our target group was dental students/interns while the target group of the previous study were dentists (GP). We also found that students from younger years had better LCU knowledge than seniors and interns, which may be due to how recently they have learned that information. The light-curing device and its types, components, and intensities are usually taught in the first clinical year of dental school. However, more than half of the students $(55.8 \%)$ were unaware that increasing the curing time negatively affects the pulp. Photopolymerization generates heat that could damage the gingival and pulpal tissues. Although dentin behaves as an isolator when there is less than $1 \mathrm{~mm}$ of dentin remaining, it should be a cause for concern [1]

A study also done in Riyadh city compared their results to a study was done in India and their lightcuring devices were superior to those measured in India. Different studies showed many different values and that directly relates to the maintenance and the quality of care for their light-curing devices [10]. Another study concluded that to achieve, the best photopolymerization effectiveness a protocol of preventive maintenance for LCUs should be enforced on the dental staff [3].

A study done in Brazil observed that $90 \%$ of the light sources measured in a dental university in Goiânia, which had fractures and cracks, remaining composite on the transmitter tip as well as an adhesive agent on the tip. As for the intensity of the light source, $55 \%$ of them showed densities lower than $300 \mathrm{~mW} / \mathrm{cm}^{2}$ [6]. In this study, the inadequate intensity standard was $\left(\leq 400 \mathrm{~mW} / \mathrm{cm}^{2}\right)$ and only 22 LCUs $(12 \%)$ were of that group. 
This study showed that $746.6485 \mathrm{~mW} / \mathrm{cm}^{2}$ was the mean value of light cure intensity which was slightly lower than a study done in Riyadh measuring light cure intensities in private clinics. Their mean value was $862.3 \mathrm{~mW} / \mathrm{cm}^{2}$ [14]. Another study done in private clinics in cities Dammam and Khobar also found a higher mean intensity of LED light-curing units, which was $865.2 \mathrm{~mW} / \mathrm{cm}^{2}$ [15]. That difference in mean value could be due to higher maintenance in private clinics.

One of the limitations in our study was that some clinics did not know the exact age of their LCUs nor provide us with company names; therefore, we could not relate the age/company to the efficacy of the LCU.

\section{Conclusion}

Most of the respondents had poor knowledge about light cure intensity. Our results agree with previous studies concluding that dental clinicians or future dental clinicians in our case have poor knowledge and the dental schools' curriculums should pay attention to that void and work on the educational system in regards to knowledge about LCUs. In addition to altering the curriculums, students in clinical years should be evaluated on their correct use of the LCU, such as making sure they check the tip for fractures or resin remnants. As well as being tested on their knowledge regarding LCUs every month to ensure their knowledge is sufficient. Another suggestion is to include radiometers if not in every clinic at least one in every dental hospital while training the students on how to use it to monitor how efficiently the LCU is working.

\section{References}

1. Krämer N, Lohbauer U, García-Godoy F, Frankenberger R. Light curing of resin-based composites in the LED era. Am J Dent. 2008;21(3):135-42.

PMid:18686762

2. Maghaireh GA, Alzraikat $\mathrm{H}$, Taha NA. Assessing the irradiance delivered from light-curing units in private dental offices in Jordan. J Am Dent Assoc. 2013;144(8):922-7. https://doi. org/10.14219/jada.archive.2013.0210

PMid:23904579
3. Gonçalves LS. Clinical effectiveness of light-curing units of the School of Dentistry of the Federal University of Goias. Rev Sul Bras Odontol. 2013;10(3):228-33.

4. Nassar HM, Almutairi M, Makhdom A. Irradiance of different curing modes of common light cure devices: An in vitro study. $\mathrm{J}$ Int Soc Prevent Community Dent. 2020;10:177-82. https://doi. org/10.4103/jispcd.jispcd_496_19

PMid:32670906

5. Strazzi-Sahyon H, Rocha E, Assunção W, Dos Santos $P$. Influence of light-curing intensity on color stability and microhardness of composite resins. Int $\mathrm{J}$ Periodontics Restorative Dent. 2020;40(1):129-34. https://doi.org/10.11607/ prd.4437

PMid:31815983

6. Hadole PG, Daokar SS. Light-curing unit (devices). Int J Orthod Rehabil. 2019;10:121-33. https://doi.org/10.4103/ijor.ijor_1_19

7. Martin FE. A survey of the efficiency of visible light curing units. J Dent. 1998;26(3):239-43.

PMid:9594476

8. Milly $\mathrm{H}$. Evaluating the clinical use of light-emitting diode vs halogen photocuring units. Oral Health Prev Dent. 2018;16(1):21-5.

PMid:29459904

9. Bansal R, Bansal M, Walia S, Bansal L, Singh K, Aggarwal R. Assessment of efficacy and maintenance of light-curing units in dental offices across Punjab: A clinical survey. Indian J Dent Sci. 2019;11:42-5. https://doi.org/10.4103/ijds.ijds_63_18

10. Al Shaafi M, Maawadh A, Al Qahtani M. Evaluation of light intensity output of QTH and LED curing devices in various governmental health institutions. Oper Dent. 2011;36:356-61. https://doi.org/10.2341/10-247-o

PMid:21834709

11. Nassar HM, Ajaj R, Hasanain F. Efficiency of light curing units in a government dental school. J Oral Sci. 2018;60(1):142-6. https://doi.org/10.2334/josnusd.17-0071

12. Sartori N, Knezevic A, Peruchi LD, Phark JH, Duarte S. Effects of light attenuation through dental tissues on cure depth of composite resins. Acta Stomatol Croat. 2019;53(2):95-105. https://doi.org/10.15644/asc53/2/1 PMid:31341317

13. Fowler CS, Swartz ML, Moore BK. Efficacy testing of visible-light-curing units. Oper Dent. 1994;19(2):47-52. PMid:8008610

14. Alqabbaa LM, Alsenani MS, Alsaif NS, Alsaif RA, Binalrimal SR. Light intensity output of visible light communication units and clinicians' knowledge and attitude among Riyadh private clinics. J Conserv Dent. 2018;21:667-70. https://doi.org/10.4103/jcd. jcd_252_18 PMid:30546216

15. Alquria T, Al Gady M, Khabeer A, Ali S. Types of polymerisation units and their intensity output in private dental clinics of twin cities in Eastern Province, KSA; a pilot study. J Taibah Univ Med Sci. 2018;14(1):47-51. https://doi.org/10.1016/j. jtumed.2018.11.008

PMid:31435389 